\title{
Combined correction of atrial septal defect, severe pectus excavatum and hydrocele in a young adult male Zaman $\mathrm{T}^{1}$, Sabur $\mathrm{S}^{2}$, Ali $\mathrm{S}^{3}$, Rahman MMS ${ }^{4}$, Bhuiyan MA ${ }^{5}$, Begum $\mathrm{M}^{6}$
}

Abstract

Pectus Excavatum (PE) is normally an isolated congenital disorder, but it can also occur with congenital heart defect (CHD). The surgical strategy has evolved over the last 20 years from staged repair to simultaneous repair of both defects. We present a case of using the Nuss procedure for PE during atrial septal defect (ASD) .

A 29 year old male possess detectable systolic murmur along with exertional dyspnea, fatigue of NYHA Class -II functional status and PE. Correction of these morbidities, a surgery was conducted in the Cardiac Surgery Department in July 2017 in Bangladesh Specialized Hospital, Dhaka. Doing a full midline incision, ASD was repaired after Cardiopulmonary bypass was done. The PE correction was done simultaneously with ASD correction. After completion of chest closure, the left sided non-communicating hydrocele was operated on, and tunical sac was excised and averted. After convalescing uneventfully, the patient was discharged.This case shows that in carefully selected cases with concomitant PE and ASD, a combination of the Nuss procedure and ASD repair and also correction of hydrocele.

CBMJ 2018 January: vol. 07 no. 01 P: 35-39

Keywords: Atrial septal defect, Nuss procedure, Pectus excavatum, Simultaneous repair

\section{Introduction}

Pectus Excavatum (PE), or funnel chest, is the most common congenital abnormality of the chest wall, with an estimated incidence of 1 in 400 births and prevalence of $2.6 \%$ in children age 7 to 14 years. PE accounts for $90 \%$ of all chest wall deformities and affects 5 times more males than females. Similarly, Atrial Septal Defect (ASD) remains to be the commonest of congenital cardiac disease with an estimated birth prevalence of 1.6 per 1000 live births and a $97 \%$ probability of survival into adulthood. However, the co-existence of the two is not so common. Only $0.17 \%$ to $0.50 \%$ of ASDs have been reported to be complicated with the presence of an anterior thoracic deformity. The majority of reports and review articles regarding correction of this combination have focused on infants and children. Traditionally, the approach to this problem has been to repair each one with a separate surgical procedure because of fear of increased complications from bleeding, infections, and anesthesia. Reports of simultaneous repair in adults are rare. Herein, we report a case of a 29 year old male patient who underwent combined correction of Pectus excavatum, closure of ASD Secundum and excision of left sided hydrocele.

\section{Case Report}

A 29 year old male presented with exertional dyspnea and fatigue of NYHA Class - II functional status. A clinically detectable systolic murmur of $2 / 6$ intensity and a wide, fixed, splitted second heart sound having highest intensity in pulmonary area were present. He also presented a Pectus excavatum with a calculated Haller Index of 3.7 (a Haller Index of 3.25 is considered severe) and a left sided Hydrocele. Externally, the PE measured a depression of more than 2 inches from the level of manubrium.

1. Dr. Tanveer Zaman, Associate Consultant, Cardiac Surgery, Bangladesh Specialized Hospital (BSH), Dhaka.

2. Dr. SAMA Sabur, Ex-Professor and Head of the Department, Department of Cardiac Surgery, National Institute of Cardiovascular Diseases (NICVD), Dhaka.

3. Dr. Shaukat Ali, Consultant, Cardiac Surgery, Bangladesh Specialized Hospital (BSH), Dhaka.

4. Dr. MM Shahidur Rahman, Consultant, Cardiac Anaesthesia, Bangladesh Specialized Hospital (BSH), Dhaka.

5. Dr. MA Bhuiyan, Registrar, Cardiac Surgery, Bangladesh Specialized Hospital (BSH), Dhaka.

6. Dr. Mahfuza Begum, Registrar and Specialist, Cardiac Surgery, Ibrahim Cardiac Hospital \& Research Institute (ICH\&RI), Dhaka.

Address of correspondence:

Dr. Tanveer Zaman, Associate Consultant, Cardiac Surgery, Bangladesh Specialized Hospital (BSH), 21, Shyamoli, Mirpur Road, Dhaka 1207.

Email: tanveerzaman@yahoo.com

Mobile: 01819230270 


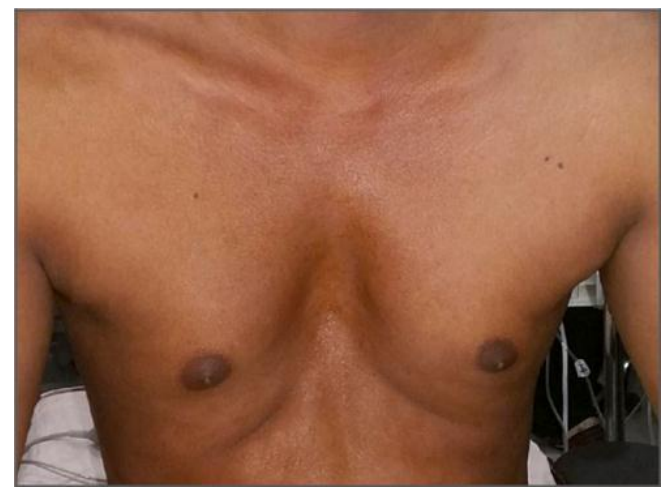

Figure 1: Frontal view of PE

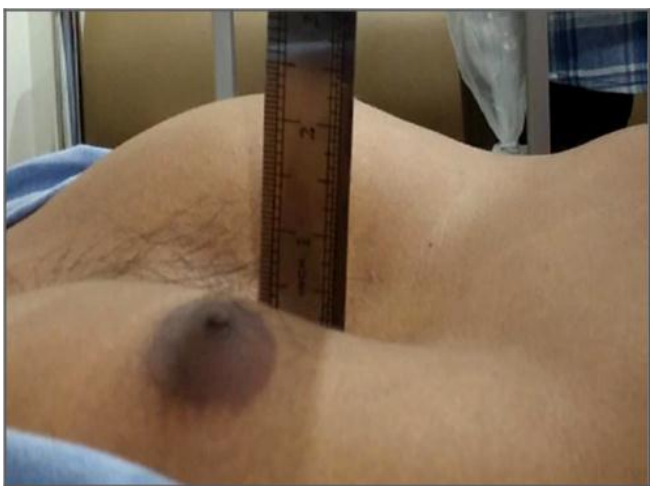

Figure 2: Surface depth of PE more than 2 inches His transthoracic echocardiogram (TTE) described an ASD Secundum measuring $31 \mathrm{~mm} \times 35 \mathrm{~mm}$ with left to right shunt, dilated right atrium and right ventricle with features of volume overload, trivial tricuspid regurgitation, moderate pulmonary hypertension (PASP $47 \mathrm{~mm} \mathrm{Hg}$ ), good biventricular function (LVEF 65\%). A transesophageal echocardiogram (TEE) appended that aortic and inferior vena caval rims of the ASD were deficient precluding device closure. A lung function test showed a severe restrictive abnormality.

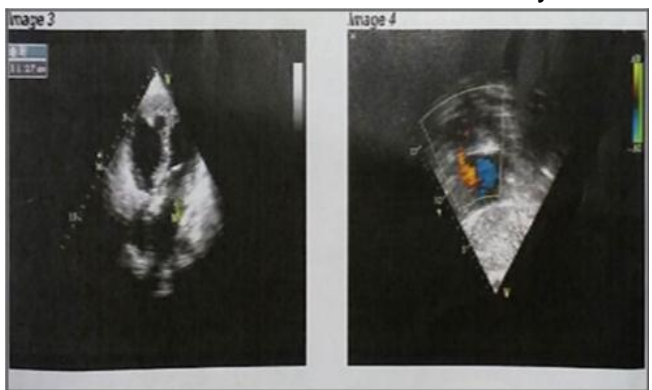

Figure 3: Transthoracic Echocardiogram
Under general anaesthesia, a full midline incision was done. Cardiopulmonary bypass was instituted through aortic and selective bicavalcannulations. ASD was repaired with a pericardial patch in standard fashion. After weaning from bypass and decannulation, protaminization was done to counteract heparin.

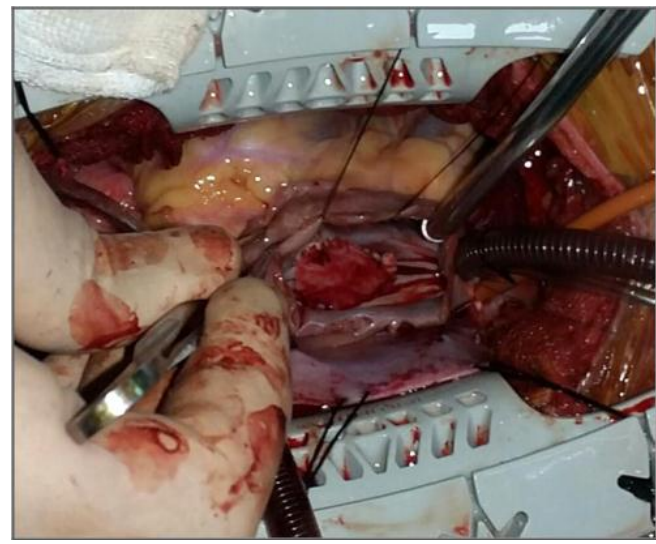

Figure 4: Pericardial patch closure of ASD

The Pectus Excavatum correction was largely based on Ravitch procedure of open correction, since a surgical correction of ASD was being undertaken. At an ACT of 120 seconds, pectoralis muscle flaps were raised on both sides of the sternum to expose the malformed costal cartilages.

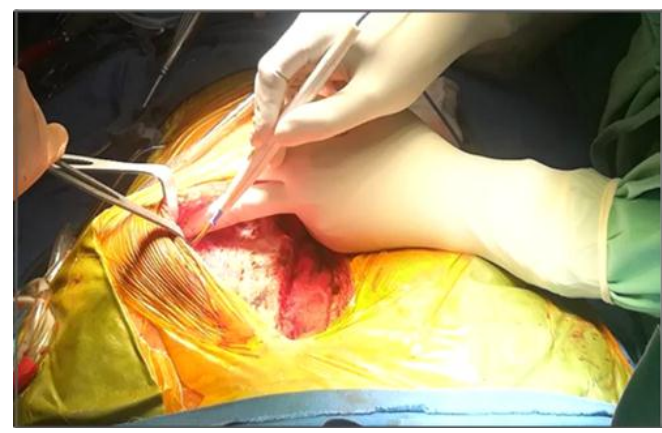

Figure 5: Raising pectoralis major flap 


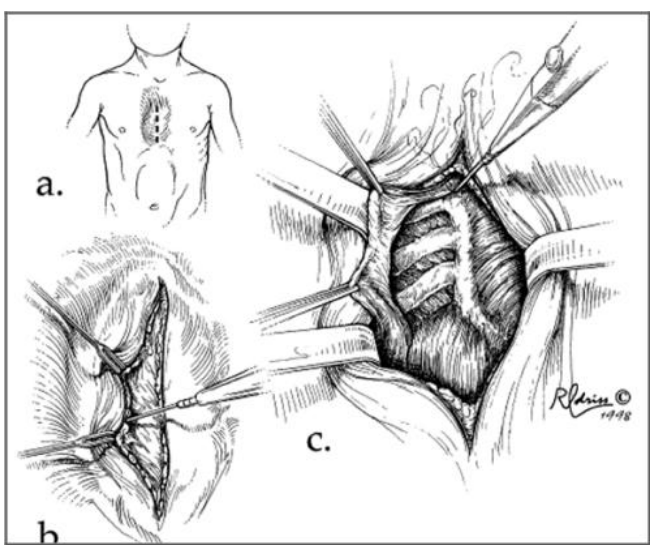

Figure 6: Schematic drawing of raising pectoralis major flap. Source: Willekes et al (1999).

After raising the flaps, subperichondreal resection of 4th, 5th and 6th costal cartilages were done on both sides. Anterior sternal osteotomy and wedge resection of anterior table of the upper end of the body of sternum was done with chisel and hammer, leaving posterior table intact but amenable to bending. Since median sternotomy was not closed, this had to be done separately on both halves of sternum.

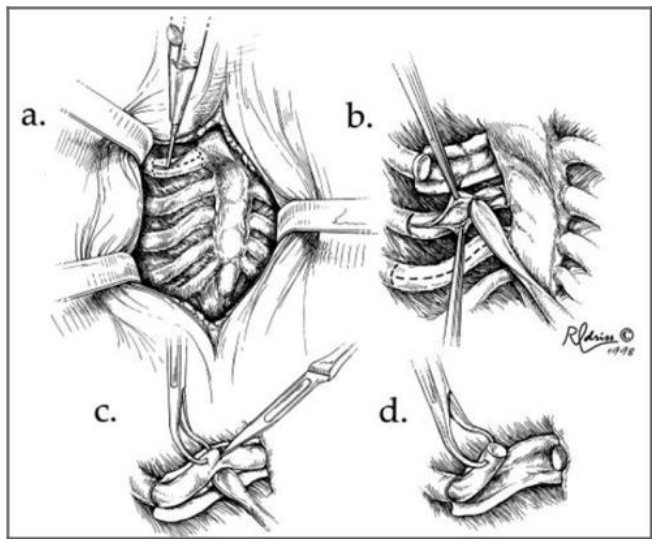

Figure 7: Schematic drawing of subperichondreal resection of deformed costal cartilages. Source Willekes et al (1999).

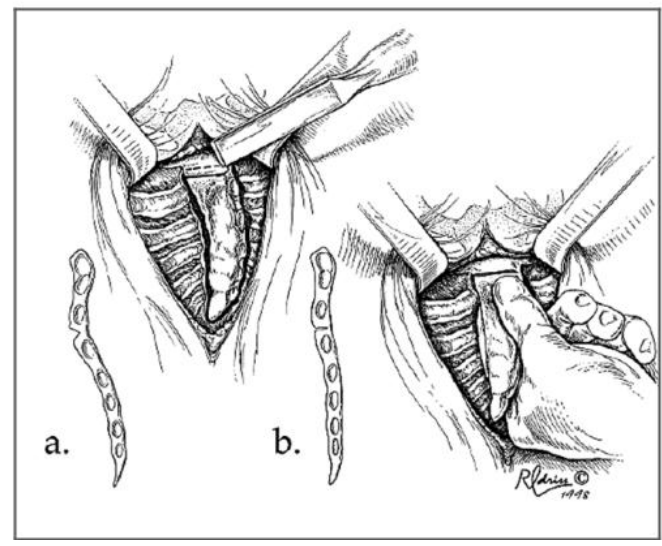

Figure 8: Schematic drawing of anterior sternal osteotomy. Source: Willekes et al (1999).

Wires were passed through bone, longitudinally from manubrium to body of sternum on both sides, which, when tightened, raised the sternal body ventrally. Unlike classical Ravitch procedure, in which a single wide metallic bar is passed, here, we passed three metallic struts sub-sternally from right to left through 4th, 5th and 6th intercostal spaces on both sides to keep the body of sternum elevated for 1 to $1 \frac{1}{2}$ years and aid a corrected remodeling. The ends of struts were fixed to the surrounding muscles.

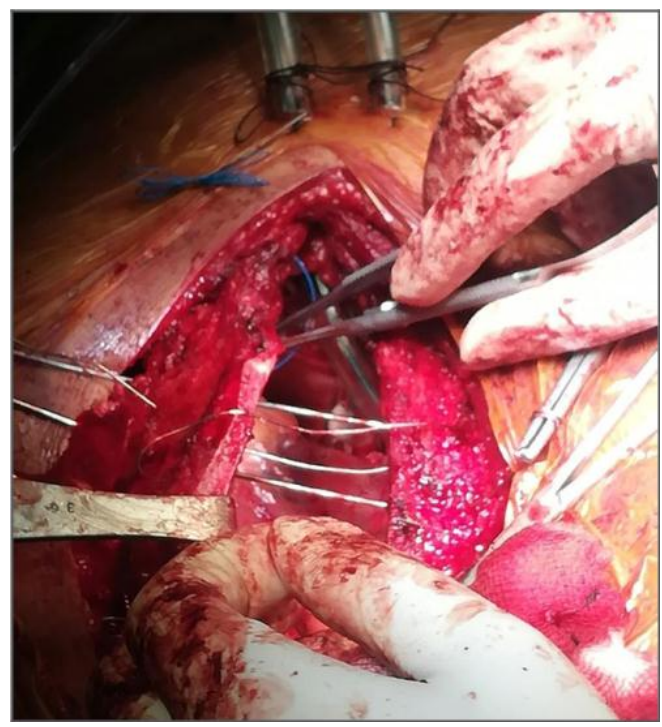

Figure 9: Placement of sub- sternal horizontal metallic struts to elevate body of sternum. 
Median sternotomy was closed with wires in a normal fashion leaving mediastinal drain tubes and pacing wire in situ. Two vaccum suction drains were placed beneath the soft tissue flaps on both sides before skin and soft tissue closure.

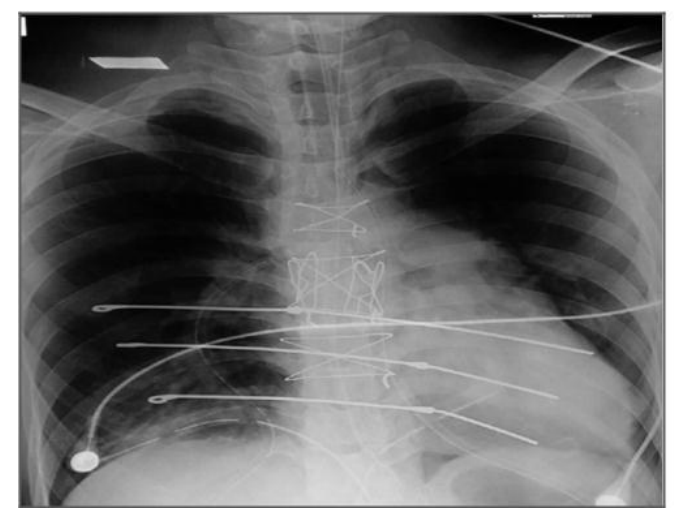

Figure 10: Chest $X$-ray showing 3 metallic struts passing beneath the sternal body.

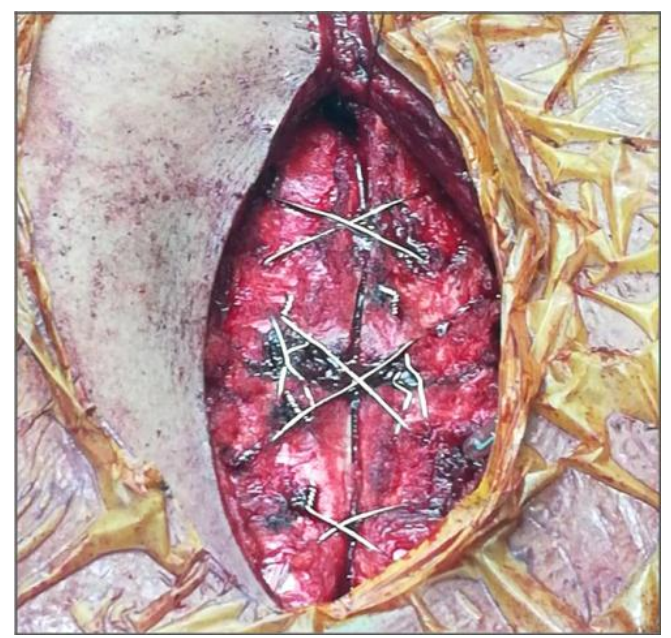

Figure 11: After sternal closure

After completion of chest closure, the left sided non-communicating hydrocele was operated on, and tunical sac was excised and everted according to Jaboulay's procedure.

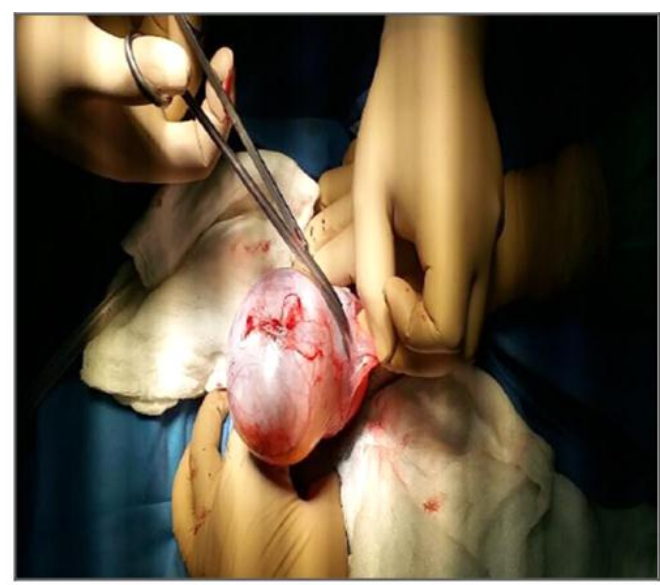

Figure 12: Jaboulay's procedure on left sided hydrocele

The patient was electively ventilated for 4 hours and 20 minutes and then extubated. Mediastinal drains were removed on the second post-operative day (POD). Vaccum suction parietal drains on the chest wall were removed on the 4th POD. Pacing wire was also removed on the 4th POD. He was shifted to his cabin on the 5th POD.

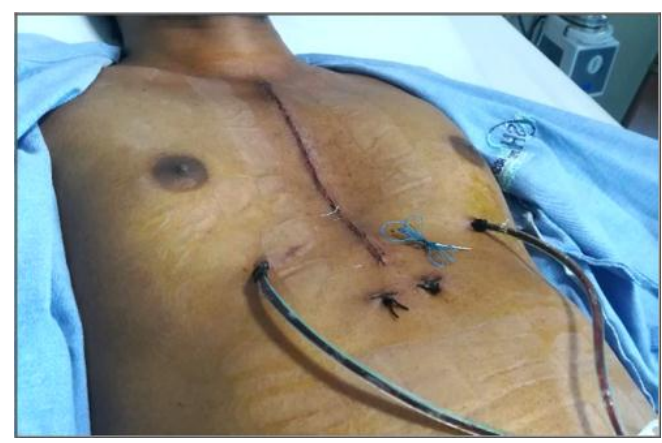

Figure 13: 2nd Post-op day, after removal of mediastinal drains.

After convalescing uneventfully, the patient was discharged on the 7th POD after having an assisted shower. Measurement of his PE was taken and found to be less than 1 inch. 


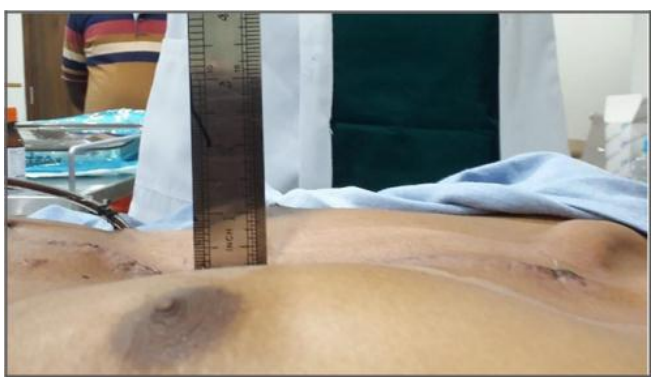

Figure 14: Surface depth of PE less than 1 inch

\section{Discussion}

Though novel minimally invasive techniques i.e. Nuss procedure is now presentfor correcting $\mathrm{PE}$, in adult patients with concomitant ASD who have already developed right heart chamber dilatation and obliteration of anterior mediastinal space, considerable risk entails in passing Nuss bars horizontally beneath the sternum without direct vision. Therefore, a staged procedure of device closure of ASD, followed by a minimally invasive Nuss procedure maybe advisable in the adults after chamber size regression.

However, in this case, a device closure was not an option due to deficient ASD rims for device engagement. A staged procedure of surgically correcting ASD followed by correction of PE at a later date may have been impossible because of an uncorrected PE compressing the operated heart causing haemodynamic instability post-operatively. Hence, an open combined procedure is found to be more feasible and good results can be yielded.

\section{Bibliography}

1. DeLeon MM, Magliato KE, Roughneen PT, et al. Simultaneous repair of pectus excavatum and congenital heart disease. Ann Thorac Surg. 1997;64:557-9.

2. Doty DB, Hawkins JA. A Turnover operation for pectus excavatum at the time of correction of intracardiac defects. J Thorac Cardiovasc Surg. 1983;86:787- 90.

3. Fonkalsrud EW, Salman T, Guo W, Gregg JP. Repair of pectus deformities with sternal support. $J$ Thorac Cardiovasc Surg. 1994;107:37- 42.
4. Haller JA, Scherer LR, Turner CS, Colombani $P M$. Evolving management of pectus excavatum based on a single institutional experience of 664 patients. Ann Surg. 1989;209:578-83.

5. Nuss D, Kelly RE Jr, Croitoru DP, Katz ME. A 10year review of a minimally invasive technique for the correction of pectus excavatum. J Pediatr Surg 1998;33:545-52.

6. Okamura T, Nagase Y, Mitsui F, Shibairi M, Utsumi K, Watanabe H. Simultaneous repair of pectus excavatum and congenital heart defect in adults by using the convex bar. Ann Thorac Surg. 2004;77(5):1827-9.

7. Ravitch MM. The operative correction of pectus excavatum. Ann Surg. 1949; 129:429.

8. Robicsek F, Daugherty KH, Mullen DC, Harbold NB, Hall DG, et al. Technical considerations in the surgical management of Pectus Excavatum and Carinatum. Ann Thorac Surg. 1974;16(6):549-562.

9. Willekes CL, Backer CL, Mavroudis C. A 26Year review of pectus deformity repairs, including simultaneous intracardiac repair. Ann Thorac Surg. 1999;67:511-8 